УДК 616.381-002.3-089

DOI

\title{
ВЫБОР ХИРУРГИЧЕСКОЙ ТАКТИКИ ПРИ РАСПРОСТРАНЕННОМ ГНОЙНОМ ПЕРИТОНИТЕ
}

\section{ФУ. Б. Абдуллаев, К. Р. Тагаев}

Самаркандский Государственный медицинский институт,

Самаркандский филиал Республиканского научного центра экстренной медицинской помощи, Республика Узбекистан

РЕЗЮМЕ. В статье сопоставляются преимущества и недостатки традиционного способа лечения распространенного гнойного перитонита и программированных релапаротомий. Исследования показали, что программированная релапаротомия является эффективным методом в предупреждении развития гнойных осложнений брюшной полости и тем самым способствует снижению количества осложнений и летальности.

КЛЮЧЕВЫЕ СЛОВА: распространенный гнойный перитонит, программированная релапаротомия.

Актуальность. До настоящего времени летальность при распространенном гнойном перитоните (РГП) сохраняется на уровне 32,0-43,9\% $[1,5,11]$, а в случаях генерализации инфекции и развития полиорганной недостаточности достигает 75,8-100 \% [7, 9, 10]. В лечении тяжелых форм острого разлитого перитонита предпочтение в настоящее время отдается лапаростомии и программированной релапаротомии $[1,3,4,8$, 11]. Они позволяют не только эффективно санировать брюшную полость, но и контролировать течение перитонита. Эти методы, являясь достаточно травматичными вмешательствами, не лишены таких недостатков, как эвисцерация, дегидратация, реинфекция, потеря белков с экссудатом, образование кишечных свищей [10]. Дискутабельным остается режим санации брюшной полости, который определяется, как правило, в процессе первого оперативного вмешательства. В подавляющем большинстве работ запрограммированные ревизии брюшной полости осуществлялись через 24-48 часов [2, 3, 9]. Однако некоторые авторы [6] высказывают мнение, что релапаротомию следует выполнять на 3-4-е сутки после первого вмешательства, основываясь на данных рентгенологического исследования, клинико-лабораторных и УЗИ симптомах. Предметом споров служит и объем санационных вмешательств при РГП.

Таким образом, вопрос о выборе оптимальной тактики хирургического лечения РГП на сегодняшний день окончательно не решен. Не существует единого мнения в вопросе выбора методов хирургического лечения, режима санации брюшной полости, обработки брюшной полости, критериев завершения основного этапа хирургического лечения.
Целью исследования явилась оценка результатов лечения больных распространенным гнойным перитонитом при использовании программированной релапаротомии.

Материалы и методы. Нами были проанализированы результаты обследования и хирургического лечения 205 больных РГП, находившихся на лечении в хирургическом отделении Самаркандского филиала РНЦЭМП в 2004-2014 гг. Мужчин было 145 (70,7 \%), женщин - 60 (29,3 \%), в возрасте от 20 до 72 лет. В первые 12 часов поступили 10 (4,9\%) больных, от 12 до 24 часов $31(15,1 \%)$, от 24 до 48 часов - 49 (23,9\%), от 48 до 72 часов - 59 (28,9\%), а свыше 72 часов - 56 $(27,3 \%)$ пациентов.

В соответствии с поставленной целью исследования все больные РГП были разделены на две группы.

Контрольную группу составили 64 (31,2 \%) больных РГП, получавших традиционное (общепринятое) лечение согласно разработанному в клинике протоколу ведения больных РГП. В процессе дальнейшего лечения 34 (53,1 \%) больным контрольной группы из-за наступивших в раннем послеоперационном периоде осложнений, связанных с основной патологией, была выполнена релапаротомия «по-требованию».

Основную группу составили 141 (68,8 \%) пациентов с РГП, у 73 (51,8 \%) из которых при поступлении в стационар по ПИМ и уровню ИАГ прогнозировалось осложненное течение перитонита. У них во время выполнения первой операции заведомо планировалось проведение программированных релапаротомий в раннем послеоперационном периоде.

Наиболее частыми причинами развития РГП были острый гангренозно-перфоративный ап- 
Огляди літератури, оригінальні дослідження, погляд на проблему

пендицит - у 70 (34,1 \%), перфорация гастродуоденальных язв - у 56 (27,3 \%), травматические повреждения полых органов брюшной полости - у $33(16,1 \%)$ и острая кишечная непроходимость у 17 (8,3 \%) больных. Также РГП наблюдался при остром панкреонекрозе, перфорации брюшнотифозных язв тонкого кишечника, болезни Крона, остром деструктивном холецистите, перфорации распадающейся опухоли толстого кишечника, остром тромбозе мезентериальных сосудов и гинекологическом перитоните.

В своей работе мы придерживались классификационно-диагностической схемы перитонита, предложенной В. С. Савельевым и соавт. (2000).

Проведенный анализ клинического материала показал четкую зависимость тяжести состояния больных от срока, прошедшего от начала заболевания. Так, РГП без признаков сепсиса наблюдался у 94 (45,9 \%) больных, септическая стадия - у 63 (30,7 \%), тяжелый сепсис - у 41 (20,0 \%), септический шок у 7 (3,4 \%), причем большинство больных с тяжелым сепсисом и септическим шоком поступили спустя 72 часа.

Для оценки тяжести состояния больных и прогнозирования исхода перитонита, а также выбора оптимальной лечебной тактики мы использовали перитонеальный индекс Мангейма (ПИМ), предложенный M. M. Linder и соавт. (1987). Большую часть исследованных нами больных составили больные со II и III степенью ПИМ (40,0 и 13,7 \% соответственно), где прогнозируемая летальность по R. Függeг и соавт. (1988) составляла при II степени до 30 \% и при III степени до $100 \%$.

Всем пациентам при поступлении в стационар и в дальнейшем, на этапах исследований, проводили общепринятые клинические методы обследования. Синдром эндогенной интоксикации (СЭИ) определяли путем изучения ЛИИ по формуле, предложенной В. К. Островским (1983), считая ее наиболее удобной и легко рассчитываемой. В выявлении СЭИ в клинике наиболее информативными оказались показатели МСМ в крови. Нами при проведении настоящих исследований была использована методика Н. И. Габриэляна и соавт. в модификации А. С. Владыки и соавт. (1986). Учитывая роль инфицирования брюшной полости в развитии гнойно-некротического процесса и токсемии, являющихся основным патогенетическим звеном развития септического состояния, при каждой операции осуществляли забор материала из брюшной полости для проведения микробиологического анализа, который включал изучение видового состава микрофлоры, определение чувствительности к антибиотикам и определение колониеобразующих единиц в 1 мл экссудата по модифицированному нами способу (рац. предл. №1584, СамГосМИ от 28.10.08 г.). Несмотря на всю значимость клинических и лабораторных данных, решающее значение в постановке точного диагноза и выборе тактики лечения пациентов имели инструментальные методы исследования (УЗИ, рентгенография, КТ, лапароскопия). Из специальных методов исследования до, во время операции и в послеоперационном периоде у больных измерялось внутрибрюшное давление через мочевой пузырь с целью выявления интраабдоминальной гипертензии (ИАГ).

Результаты исследования. Главной целью комплекса лечебных мероприятий, проводимых больным контрольной группы РГП, явились раннее оперативное вмешательство с устранением источника перитонита, эвакуация экссудата, санация и тщательный лаваж брюшной полости с декомпрессией кишечника посредством двухканального назоинтестинального зонда, новокаинизация корня брыжейки тонкого кишечника и дренирование брюшной полости. Оперативное вмешательство у больных этой группы заканчивали послойным сшиванием послеоперационной раны.

В послеоперационном периоде всем этим больным проводили комплекс лечебных мероприятий, воздействующих на основные патогенетические звенья заболевания: нарушение гомеостаза и микроциркуляции, гипоксию, эндогенную интоксикацию, бактериальную загрязненность брюшной полости и бактериемию, ПОН. Этот комплекс мероприятий включал в себя также активную декомпрессию кишечника и целенаправленную антибактериальную терапию. Хотя мы у данного контингента больных придерживались тактики минимального оперативного вмешательства, выполненные оперативные вмешательства в большинстве случаев были радикальными.

В результате использования вышеуказанной стандартной схемы лечения у 47 (73,4 \%) выживших больных удалось добиться разрешения послеоперационного пареза кишечника лишь на 5-6 сутки. Анализ динамики восстановления показателей гемодинамики и основных биохимических параметров крови у этих больных также свидетельствовали о крайне медленной их нормализации. Из лабораторных критериев эндогенной интоксикации у данного контингента больных наиболее информативными оказались показатели МСМ в крови, которые были повышены у всех больных и в среднем на волне спектрофотометра 280 нм составили 0,352-0,015 усл. ед. Показатель ЛИИ превышал норму, в отдельных случаях достигая 10,28 усл. ед.

Клинические наблюдения и проведенные нами исследования у больных контрольной груп- 
Огляди літератури, оригінальні дослідження, погляд на проблему

пы в раннем послеоперационном периоде показали прямую корреляцию между показателями эндотоксикоза (ЛИИ, МСМ) в крови и интраоперационным определением степени тяжести состояния больных по ПИМ. Чем выше были показатели эндогенной интоксикации (ЛИИ, МСМ), тем выше оказывались баллы ПИМ и его стадии. Это, в свою очередь, прогнозировало неблагополучное или осложненное течение перитонита. В дальнейшем этот прогноз подтвердился, когда более половины больных этой группы $(53,1 \%)$ с ПИМ более 20 баллов вследствие возникших в раннем послеоперационном периоде осложнений подверглись релапаротомии «по-требованию». Хотя в диагностике данного контингента больных учитывались все объективные и субъективные данные, показатели лабораторных и инструментальных исследований, у большинства из них (20 сл.) была произведена запоздалая релапаротомия. В этом, как нам кажется, немаловажное значение имело отсутствие надлежащего контроля за течением патологического процесса в брюшной полости и ИАГ, а также достоверных критериев прогнозирования осложненного течения РГП, что в итоге привело к развитию различных специфических для этой патологии осложнений и летальных исходов.

Таким образом, анализ результатов лечения больных РГП контрольной группы показал, что в течение патологического процесса в послеоперационном периоде можно выделить 2 основных этапа. Первый этап - ранний послеоперационный период (1-5 сутки после операции), где на первом плане находится высокая эндогенная интоксикация, интраабдоминальная гипертензия, функциональная кишечная недостаточность с начальными проявлениями ПОН.

Хотя основной причиной смерти у наших больных являлась ПОН, в патогенезе её ключевая роль, несомненно, принадлежала кишечной недостаточности, способствующей генерализации токсического процесса с развитием СЭИ. Возникающие при этом системные прогрессирующие нарушения носили характер септического или инфекционнотоксического шока. Адекватность проводимого лечения на этом этапе позволила снизить уровень интоксикации и частоту внутрибрюшных осложнений, проявления функциональной кишечной непроходимости, контролировать внутрибрюшное давление, тем самым исключить возможность развития ПОН, что способствовало переходу этой категории больных в стадию разрешения перитонита и в дальнейшем к выздоровлению.

Недостатки в выполнении этих мероприятий или опоздание с ними, как это было у ряда больных контрольной группы, способствовали пере- ходу патологического процесса на второй этап стадию вялотекущего перитонита с проявлениями ПОН и вторичным осложнением перитонита. А часть больных, у которых на первом этапе не удавалось одолеть эндогенную интоксикацию, с проявлениями ПОН погибали от тяжелого сепсиса или септического шока. Сам переход заболевания на второй этап в дальнейшем требовал от клинициста значительных усилий, чтобы перевести данный контингент больных в стадию разрешения перитонита и к выздоровлению.

В связи с этим значимость первого этапа патологического процесса являлось ключевым в лечебно-диагностическом плане у больных РГП. Приложение усилий на данном этапе чаще всего определяло наибольшую эффективность проводимых лечебных мероприятий. Так, при благоприятном исходе операции (выжившие больные), начиная с 4-5-х суток появлялись перистальтические шумы, после стимуляции начинали отходить газы и стул. Живот опадал, явления интоксикации и паралитической кишечной непроходимости уменьшались и наступало выздоровление. При неблагоприятном течении РГП (умершие больные), несмотря на проводимое комплексное лечение и активную стимуляцию кишечника, паралитическая кишечная непроходимость не разрешалась в течение всего раннего послеоперационного периода, нарастали явления интоксикации, состояние больных прогрессивно ухудшалось, и возникало одно из возможных послеоперационных осложнений, которое являлось поводом для повторного оперативного вмешательства (релапаротомии «по-требованию») или наступал летальный исход.

Проведенный анализ послеоперационных осложнений у больных контрольной группы выявил высокий удельный вес возникших в раннем послеоперационном периоде гнойносептических, кишечных и бронхоплевральных осложнений, которые, по-видимому, были связаны не только с недостаточностью выполненных во время первой операции лечебных мероприятий, но и с возникающей ИАГ, а также с высоким уровнем эндогенной интоксикации и несвоевременной диагностикой последних.

Так, в контрольной группе послеоперационные осложнения наблюдались у 32,8 \% больных, а летальность составила 26,6 \% (17 больних).

Неудовлетворенность полученными результатами лечения больных контрольной группы заставила нас искать пути улучшения результатов лечения. В свете этого нам показалась очевидной необходимость разработки объективных критериев адекватной оценки уровня эндогенной интоксикации, степени тяжести течения 
Огляди літератури, оригінальні дослідження, погляд на проблему

РГП. Применяя в своей клинической практике у больных контрольной группы ПИМ, который подтверждался высокими показателями ЛИИ, МСМ с учетом ИАГ, можно было прогнозировать осложненное или неосложненное течение РГП. Это натолкнуло нас на мысль об использовании ПИМ, наряду с другими объективными показателями эндогенной интоксикации (ЛИИ, МСМ) в крови и ИАГ, в качестве достоверного критерия прогнозирования осложненного течения перитонита.

Поэтому, для оценки эффективности программированной релапаротомии в комплексе лечебных мероприятий у больных РГП и сравнения результатов лечения была подобрана и исследована основная группа больных (141 пациент) с приблизительно одинаковым составом сравниваемых параметров, по полу и возрасту, этиологическим причинам и сопутствующим заболеваниям, фазам течения перитонита и срокам поступления в стационар, что обеспечивало их рандомизированность.

Проведенные нами исследования у больных основной группы подтвердили высокий уровень показателей эндогенной интоксикации (ЛИИ, МСМ) при поступлении в стационар, наряду с высокими показателями ИАГ и ПИМ, которые свидетельствовали не только о тяжести течения патологического процесса, но и прогнозировали у 72 (51,1 \%) больных неблагоприятное или осложненное течение заболевания.

Исходя из этого, в соответствии с разработанной нами «Программой определения показаний к лапаростомиям при ОРГП» (Патент на изобр. № 01632 DGU от 22.10.2008 г.), «Программой электронного обеспечения выбора интраоперационной тактики лечения при ОРГП» (Патент на изобр. № 01674 DGU от 19.01.2009 г.), во время выполнения первой операции им заведомо планировалась программированная релапаротомия по методике В. С. Савельева и соавт. (1998) для проведения в раннем послеоперационном периоде лапаросанаций. Так, в процессе лечения наиболее тяжелому контингенту больных РГП с прогнозированием осложненного течения перитонита было выполнено 173 лапаросанации (от 1 до 5 санаций), в среднем 2,1.

В процессе выполнения настоящих исследований дополнительными объективными критериями регресса перитонита и показаниями к прекращению программированных релапаротомий и лапаросанаций служило снижение ИАГ менее 15 мм рт. ст. и концентрации микробных тел перитонеального экссудата до $10^{5}$ и менее в 1 мл.

В результате комплексного лечения больных РГП с выполнением программированных релапаротомий при благоприятном течении заболевания уже к 3-4 суткам после операции резко снижались явления интоксикации: значимо снижался лИИ (с $(2,98 \pm 0,12)$ до $(2,12 \pm 0,09), P<0,05)$, уровень МСМ (с $(0,358 \pm 0,019)$ до $(0,276 \pm 0,013), Р<0,05)$, хотя в первые двое суток наблюдения эти показатели оставались достаточно высокими. При сравнительной оценке с показателями больных контрольной группы аналогичные результаты были достигнуты только на 5-6 сутки после операции. Наряду со снижением интоксикации, при очередных лапаросанациях наблюдали регресс перитонита, снижение показателей ИАГ (менее 15 мм рт. ст.) и улучшение общего состояния больных. Клинически это проявлялось появлением перистальтических шумов, отхождением газов и стула. Живот опадал, явления интоксикации, паралитической кишечной непроходимости, а также проявления ПОН исчезали, и наступало выздоровление.

В отличие от этого, у умерших больных этой группы (18 больних), несмотря на кажущийся регресс перитонита при очередных лапаросанациях, общее состояние оставалось крайне тяжелым, наблюдалось прогрессивное нарастание показателей эндотоксикоза (ЛИИ, МСМ) и ИАГ (более 15 мм рт. ст.) с выраженными клиническими признаками острой печеночной и почечной недостаточности. Несмотря на проводимое комплексное лечение (активная декомпрессия и стимуляция кишечника), паралитическая кишечная непроходимость не разрешалась в течение всего раннего послеоперационного периода, наоборот, перерастала в функциональную кишечную недостаточность, нарастали явления интоксикации и ПОН, уже с присоединением острой сердечнососудистой и дыхательной недостаточности, состояние больных прогрессивно ухудшалось, и наступал летальный исход.

Микробиологические исследования, проведенные в динамике лечения у больных основной группы, показали, что у подавляющего большинства выживших больных имел место минимальной рост бактерий к 4-5 суткам после первой операции, тогда как у умерших концентрация микробных тел в эти же сроки оставалась на достаточно высоком уровне.

Анализ послеоперационных осложнений показал, что выявленные 37 осложнений возникли у 33 из 141 пациента основной группы, тогда как в контрольной группе было выявлено 41 осложнение, которое наблюдалось у 21 из 64 больных. Следовательно, послеоперационные осложнения в основной группе встречались у 23,4 \% больных, а в контрольной - у 32,8 \% при одинаковой тяжести РГП.

При сравнительном анализе летальных исходов выявлено, что в основной группе неблаго- 
Огляди літератури, оригінальні дослідження, погляд на проблему

приятный исход наступил у 18 (12,8 \%) больных, а в контрольной - у 17 (26,6 \%). Видимо, это было связано, главным образом, с использованием программированных релапаротомий и лапаросанаций, которые позволили снизить число ранних послеоперационных внутрибрюшных осложнений и способствовали предупреждению запоздалых релапаротомий.

\section{ЛИТЕРАТУРА}

1. Ачилов Ш. Д. Лапаростомия в комплексном лечении распространенного перитонита : дис. на соискание ученой степени канд. мед. наук. - Ташкент, 2002. $62 \mathrm{c}$.

2. Бабаджанов Б. Д. Релапаротомия в критических ситуациях абдоминальной хирургии / Б. Д. Бабаджанов, О. Р. Тешаев, У. М. Мухиддинов // Хирургия Узбекистана. - 2007, № 3, С. 50-52.

3. Выбор режима этапного хирургического лечения распространенного перитонита / Б. Р. Гельфанд, М. И. Филимонов, П. В. Подачин [и др.] // Анналы хирургии. - 2009. - № 4. - С. 5-10.

4. Гостищев В. К. Перитонит / В. К. Гостищев, В. П. Сажин, А.Л. Авдовенко. - М. : ГЭОТАР-МЕД, 2002. $240 \mathrm{c}$.

5. Ерюхин И.А. Хирургия гнойного перитонита : 80 лекций по хирургии ; под ред. В. С. Савельева. - М. : Литера, 2008. - 910 с.

6. Каншин Н. Н. Полуоткрытый метод ведения брюшной полости при запущенном перитоните / Н. Н. Каншин, Э. А. Береснева // Материалы 1-го Московского международного конгресса хирургов. - М., 2004. - С. 11-12.
Выводы. Использование программированной релапаротомии в комплексном лечении у подавляющего большинства больных с распространенным гнойным перитонитом способствовало купированию воспалительного процесса в брюшной полости, снижению интоксикации по всем исследуемым параметрам, улучшению общего состояния и выздоровлению.
7. Роль и место длительной внутриартериальной катетерной терапии в лечении гнойного перитонита / Ш. И. Каримов, А. А. Асраров, М. Ш. Хакимов [и др.] // Актуальные проблемы гнойно-септической хирургии : Материалы Респ. науч.-практ. конф. - Бухара, 2010. C. $164-165$.

8. Подачин П. В. Показания к этапному хирургическому лечению распространенного перитонита / П. В. Подачин, С. В. Чубченко // Неотложная и специализированная хирургическая помощь : 2-ой конгресс московских хирургов. - М., 2007. - С. 69.

9. Савельев В. С. Перитонит / В. С. Савельев, Б. Р. Гельфанд, М. И. Филимонов. - М. : Литтера, 2006. 213 c.

10. Тешаев О. Р. Разработка критериев и оценка эффективности фазового подхода в лечении воспалительного процесса при острых распространенных перитонитах : дис. на соискание ученой степени д-ра мед. наук. - Ташкент, 2002.

11. Шуркалин Б. К. Хирургические аспекты лечения распространенного перитонита / Б. К. Шуркалин, А. П. Фаллер, В. А. Горский // Хирургия. - 2007. №2. - С. 24-28.

\section{THE CHOICE OF SURGICAL TACTICS WHEN WIDESPREAD PURULENT PERITONITIS} OU. B. Abdullayev, K. R. Tahayev

\section{Samarkand State Medical Institute, Samarkand Branch of Republican Scientific Centre of Emergency Medical Aid, Republic of Usbekystan}

SUMMARY. The article adduces the advantages and disadvantages of the traditional way of the treatment of the widespread festering peritonitis and programmed relaparotomy. The studies have shown that programmed relaparotomy is an efficient method in warning the development of the festering complications to abdominal cavity and hereunder, promotes the reduction of the complications and death-rate.

KEY WORDS: widespread purulent peritonitis, programmed relaparotomy. 